\title{
ESTIMATION OF COMPONENTS OF PHENOTYPIC VARIANCE FOR DEVELOPMENTAL RATE IN TRIBOLIUM*
}

\author{
PETER S. DAWSON \\ Department of Genetics, University of California, Berkeley, California
}

Received 20.iii.65

\section{INTRODUCTION}

PRIOR to conducting extensive genetic studies on populations of a species, particularly with respect to a single character, it is important to know of the extent of different sources of phenotypic variation. Since Fisher's (1918) monumental work on partitioning of variance, this aspect of population genetics is one in which theoretical studies have become increasingly more refined than experimental investigations (see Cockerham, 1956). It is worthwhile, therefore, to test empirically as many of the methods as possible using the same foundation stocks as sources of experimental material.

Estimates of components of phenotypic variance have been reported for many characters in a number of species (see, for example, Lerner, $195^{8}$ Falconer, 1960), but a comprehensive comparison of estimates derived from several different methods is not available.

In the course of investigations (Dawson, $1964 b$ ) on the genetics of developmental rate and the role of developmental rate in interspecific competition in flour beetles of the genus Tribolium, the results of which will be reported in subsequent papers, an extensive series of experiments was carried out to provide estimates of various components of phenotypic variance. This report summarises and compares these results.

\section{MATERIALS AND METHODS}

The University of California synthetic stocks of two species of flour beetles, Tribolium castaneum (hereafter referred to as CS) and $T$. confusum (CF), were utilised as foundation populations for all experiments reported here. These stocks were synthesised in 1958 from several diverse laboratory and natural sources and have been maintained as closed populations since that time (details in Lerner and Ho, Ig6r).

Six experimental designs were employed to obtain estimates of variance components for developmental rate:

(I) Comparison of means and variances of highly inbred lines, $F_{1}, F_{2}$ and backcross progenies.

(2) Parent-offspring regression with random mating of parents.

(3) Parent-offspring regression with assortative mating of parents.

(4) Full and half-sib nested design.

(5) A number of 2 sire, 2 dam diallel matings.

(6) Comparison of variances in outbred populations and $F_{1}$ hybrids between inbred lines.

- Part of a dissertation submitted to the Graduate Division, University of California, in partial fulfilment of the requirements for the degree of Doctor of Philosophy in Genetics. 
All six designs were utilised for CS; for CF (3) and (4) were not carried out. In addition to estimates of heritability and other parameters obtained from these methods, realised heritability estimates were available from lines selected for fast and slow development starting with the same foundation material and from selection in $F_{2}$ populations formed by crossing inbred lines.

Of these six methods, (2) to (5) were applied to data obtained using small shell vials $(\mathrm{I} 5 \times 45 \mathrm{~mm}$.) initially seeded with ten eggs in approximately $\mathrm{I} \cdot 5 \mathrm{~g}$. of flour. All parents used were selected from individuals obtained from a random sample of eggs from the synthetic strains. Two small preliminary tests were carried out with CS to see if there were any density effects on developmental rate (where density is defined as the number of papæ obtained per vial). The results did not indicate any significant density effects on either mean or variance. For the remaining two methods, larger vials $(25 \times 95 \mathrm{~mm}$.) and a variable number of eggs were used. The densities in these cultures were low enough so that no corrections for effect of density on developmental rate had to be applied.

The character utilised in these experiments was the number of days from egg to pupa. Pupation time was chosen in preference to the time of adult emergence principally because it insured that all females used in further matings would be virgin.

Techniques used to measure developmental time are described in detail by Dawson (1964a). Briefly, for designs (2) to (5) listed above, at a specified time of day adult females which had been with males for at least two days were placed in very fine white flour. At the same time on the following day the females were removed and ten eggs were later collected and placed in small vials in a standard flour mixture (stone-ground whole-wheat flour enriched with 5 per cent. brewer's yeast). When pupation began, all vials were checked daily, again at the same time. Flour was sifted from the vials, the pupæ were removed and the remaining larvæ were returned to the vials.

Parental beetles used in these experiments were obtained from vials which had been handled in the same way except that random samples of ten eggs from the synthetic stocks (all less than 24 hours of age) were initially placed in the cultures.

For designs (I) and (6), a slightly different procedure was used. A known number of parents was introduced into a large vial at a specified time. On the following day, again at the same time, the parents were removed. The number of eggs in these vials was not known but was to some extent regulated by the numbers of adults used. Pupation time was scored in the same way as for the small vials.

All cultures were maintained in a converted Jamesway Poultry Incubator at $29^{\circ} \mathrm{C}$. and 70 per cent. relative humidity. Attempts were made to reduce as much as possible the length of time that cultures were out of the incubator.

Developmental time in both synthetic populations is not normally distributed (see also Howe, 1961), and logarithmic and square root transformations failed to normalise the distributions. However, analysis of variance techniques are quite robust against non-normality (Box, 1953; Scheffé, 1959, p. 360). Vial means were used whenever possible to eliminate non-normality problems.

\section{RESUL.TS}

The first experiments were designed to test for the presence or absence of epistasis using techniques developed by Mather (see 1949). Starting with one pair of inbred lines for each species, developmental rates were measured for each inbred line and for $F_{1}, F_{2}$ and backcross (BC) progenies within each pair of lines. $F_{1}$ and $B C$ data were obtained using only one of the possible reciprocal crosses. Most mating combinations were replicated from $I 5$ to 20 times in order to provide estimates of variances of vial means; in two cases only 
8 replicates were utilised. Since vial means were used the problem of non-normality was circumvented. Vial means were based on 35 to 140 individual observations.

One of the basic assumptions of this procedure is that environmental variance should be equal in the parental inbred lines and the $F_{1}$ populations. When this criterion is not satisfied, transformation of the data to a more suitable scale may equalise the variances, or at least reduce the inequalities.

The most obvious limitation of this first technique is that the inbred lines may not be at all representative of the foundation population from which they were originally derived. Even if they are a representative sample, estimates of dominance variance which can be obtained using these methods may bear little relation to the dominance variance of the original population because of the strong frequency dependence of dominance variance in the population (Dempster, personal communication). Further, Anderson and Kempthorne (1954) have shown that some types of epistasis will not be revealed using Mather's methods. Cockerham (1956) describes alternative procedures for estimating epistatic variance but these techniques, most applicable in plants, were considered to be too complex to be performed during the present investigations. In view of these objections, estimates obtained from this type of analysis would, by themselves, seem to be of little significance; however, when used in combination with other methods they might be quite useful.

Means and standard errors of vial means and the statistics used to test for epistasis are listed in table I. None of the three measures of epistasis differ significantly from zero for CS; thus epistatic interactions are apparently not an important source of variance in the two CS inbred lines and their derivatives. For GF, however, the A, B and C statistics are all significantly less than zero, indicating the presence of epistatic interactions of genes for developmental rate.

Variances of the individual observations, also given in table I indicate, however, that the assumption of equality of variance in the inbred and $F_{1}$ populations is not satisfied. A logarithmic transformation applied to the data reduced the inequalities only slightly and was therefore not utilised. Significance tests performed on the $A, B$ and $C$ statistics obtained from the transformed data gave essentially the same results although the absolute values of the ratios of $A, B$ and $\mathrm{C}$ to their standard errors were considerably smaller. This leads to the thought that a transformation powerful enough to eliminate the inequality of the variances in $\mathrm{CF}$ might also render the tests for epistasis non-significant.

In view of the problems associated with non-equality of variances, the results of this set of experiments must be regarded as inconclusive. For CS, epistatic variance does not appear to be of major importance, but the same cannot be said of CF. Since the data could not be $2 \mathrm{C}$ 
properly scaled, estimates of heritability and dominance variance would not be very meaningful and were therefore not computed.

For all further analyses presented here it will be assumed that epistasis and genotype-environment interactions do not contribute significantly to the genetic component of variance. Although the latter assumption did not hold in the inbred material, it seems unreasonable to conclude that the effects appearing in highly inbred populations are necessarily of importance in non-inbred ones. In most of the remaining experiments, individuals belonging to the same family were raised in the same vial. The estimates of genetic com-

TABLE 1

Means and standard errors (S.E.) of vial means, variances of individual observations $\left(\mathbf{s}^{2}\right)$, and statistics used in Mather's test for epistasis (see text)

\begin{tabular}{|c|c|c|c|c|c|c|}
\hline & \multicolumn{3}{|c|}{$C F \| \times 1$} & \multicolumn{3}{|c|}{ CS $3 \times 5$} \\
\hline & $\bar{x}$ & S.E. & $s^{2}$ & $\overline{\boldsymbol{x}}$ & S.E. & $s^{2}$ \\
\hline $\begin{array}{l}P_{1} \\
P_{2} \\
F_{1} \\
F_{2} \\
B_{1} \\
B C_{2}\end{array}$ & $\begin{array}{l}26 \cdot 090 \\
25 \cdot 948 \\
23 \cdot 718 \\
24 \cdot 495 \\
24 \cdot 679 \\
24 \cdot 432\end{array}$ & $\begin{array}{l}0.097 \\
0.085 \\
0.048 \\
0.070 \\
0.086 \\
0.096\end{array}$ & $\begin{array}{l}2 \cdot 496 \\
4 \cdot 189 \\
1 \cdot 112 \\
1 \cdot 615 \\
1 \cdot 495 \\
1 \cdot 451\end{array}$ & $\begin{array}{l}26 \cdot 915 \\
25 \cdot 928 \\
22 \cdot 130 \\
24 \cdot 970 \\
24 \cdot 420 \\
24 \cdot 207\end{array}$ & $\begin{array}{l}0.119 \\
0 \cdot 107 \\
0.066 \\
0 \cdot 102 \\
0 \cdot 169 \\
0.162\end{array}$ & $\begin{array}{l}4 \cdot 263 \\
6 \cdot 278 \\
2 \cdot 378 \\
6 \cdot 566 \\
5 \cdot 505 \\
5 \cdot 036\end{array}$ \\
\hline $\begin{array}{l}\mathrm{A}^{*} \\
\mathrm{~B} \\
\mathrm{C}\end{array}$ & $\begin{array}{l}-0.450 \\
-0.802 \\
-1.494\end{array}$ & $\begin{array}{l}0.162 \\
0.167 \\
0.322\end{array}$ & & $\begin{array}{r}-0.205 \\
+0.356 \\
+2.777\end{array}$ & $\begin{array}{l}0.929 \\
0.907 \\
1.456\end{array}$ & \\
\hline
\end{tabular}

ponents may be inflated if there is an important differential effect of vial environments on rate of development. However, in a small-scale test carried out utilising highly inbred lines, between-family variance was not significantly greater than within-family variance. Thus, at least in this experiment, the environmental effects mentioned above were not too important.

Parent-offspring regression analyses were made for CS only using both randomly and assortatively mated parents. The latter method, developed by Reeve (1953, 1955, 1961) increases the variance of parental values, thereby increasing the accuracy of estimation of the regression coefficient. The possible bias introduced as the result of phenotypic correlations between parents was shown to involve only second-order components (Reeve, I96I).

If regression is linear and no maternal effects are present, the covariance between offspring average and midparent value from randomly mated parents contains $\frac{1}{2} \sigma_{\mathrm{A}}^{2}$, the additive genetic variance, plus decreasing fractions of higher order additive $\times$ additive epistatic 
terms $\left(\frac{1}{4} \sigma_{\mathrm{AA}}^{2}+\frac{1}{8} \sigma_{\mathrm{AAA}}^{2}+\ldots\right)$. The variance of midparent values accounts for half of the total phenotypic variance $\left(\sigma_{\mathrm{T}}^{2}\right)$. Thus, if the epistatic components may be ignored, the regression coefficient gives an estimate of narrow sense heritability $\left(b=\sigma_{\mathrm{A}}^{2} / \sigma_{\mathrm{T}}^{2}\right)$. Due to the known presence of maternal effects on developmental rate, the regression of offspring on sire and dam was computed separately. In this case the regression coefficient estimates only one-half of the heritability (Falconer, I96o, p. 169).

For both mating designs, I20 matings were made. Only those matings producing at least five pupæ per ten eggs collected were used. This restriction left $9 \mathrm{I}$ and 99 sets of parents and offspring for the assortative and random mating analyses respectively.

TABLE 2

Estimates of heritability from parent-offspring regression using two different systems of mating of parents, with 95 per cent. confidence limits

\begin{tabular}{|c|c|c|c|c|}
\hline Mating system & Regression on & $\begin{array}{c}\text { Number of } \\
\text { matings }\end{array}$ & Heritability & $\begin{array}{c}\text { Confidence } \\
\text { limits }\end{array}$ \\
\hline Random & $\begin{array}{l}\text { Midparent : } \\
\text { Sire }: \\
\text { Dam : }\end{array}$ & $\begin{array}{l}99 \\
\cdots \\
\cdots\end{array}$ & $\begin{array}{l}0 \cdot 27 \\
0 \cdot 12 \\
0 \cdot 30\end{array}$ & $\begin{array}{r}0.03,0.50 \\
-0.26,0.50 \\
0.02,0.57\end{array}$ \\
\hline Assortative & Midparent . & 91 & 0.26 & $0.13,0.39$ \\
\hline
\end{tabular}

Heritabilities and 95 per cent. confidence limits (Snedecor, I956, p. 125) are given in table 2. Since vial means were used in these analyses, there are no non-normality problems. It is seen that, as shown by Reeve (I96I), assortative mating gives a more precise estimate. However, if maternal effects are present, a completely assortative scheme will not detect them since the regression of offspring on sire and dam will be the same. Thus, when using characters complicated by maternal effects, this method can overestimate heritability (Dawson, $1964 b$ ).

When regression of offspring on sire and on dam is performed separately for the random mating design, only the dam estimate includes variation due to maternal effects $\left(b=\frac{1}{2} h^{2}+\mathrm{M}\right)$. Thus the heritabilities given in table 2 for regression on dam include twice those maternal effects correlated with the expression of the character in the dam itself. Using the sire estimate of 0.12 for $h^{2}$ leaves 0.09 as an estimate of $M$. This maternal effect may be an underestimate or even an overestimate, depending on the hypothesis assumed. For example, on one hypothesis of completely heritable genetic maternal effects, the regression of offspring ondam estimates $\frac{1}{2} h^{2}+\frac{1}{2} \mathrm{M}$.

Another set of estimates was obtained using a full and half sib nested design (Type I of Comstock and Robinson, 1952). For both CS and CF, 30 males were mated to three females each and ten eggs 
were collected per dam. Only those sires for which at least two females produced five or more offspring were used. All CS males and 28 of the CF males fulfilled these requirements. The analysis of variance and estimates of variance components are given in table 3. Formula for coefficients of variance components in the case of unequal numbers of dams and offspring were taken from Snedecor (1956, p. 272). In such cases, exact estimates of variance components are obtained by using two different coefficients to represent the number of offspring per dam [in the E(MS) column of table 3 these two coefficients would

TABLE 3

Analysis of variance for nested designs for CS and $C F$

\begin{tabular}{|c|c|c|c|c|}
\hline Source & $\mathrm{df}$ & MS & $\mathrm{E}(\mathrm{MS})$ & Components \\
\hline A. CS & & & & \\
\hline Between sires . & 29 & $5 \cdot 949 \mathrm{r}$ & $\sigma_{\mathrm{W}}^{2}+k_{1} \sigma_{\mathrm{D}}^{2}+k_{2} \sigma_{\mathrm{S}}^{2}$ & $\hat{\sigma}_{\mathrm{S}}^{2}=0.0755$ \\
\hline $\begin{array}{c}\text { Between dams within } \\
\text { sires }\end{array}$ & $5^{6}$ & 3.9247 & $\sigma_{\mathrm{W}}^{2}+k_{1} \sigma_{\mathrm{D}}^{2}$ & $\hat{\sigma}_{\mathrm{D}}^{2}=0.2907$ \\
\hline Within full sib families & 695 & $1 \cdot 3140$ & $\sigma_{\mathrm{W}}^{2}$ & $\hat{\sigma}_{\mathrm{W}}^{2}=\mathrm{I} \cdot 3 \mathrm{I} \mathbf{4}^{\mathrm{O}}$ \\
\hline B. $\mathrm{CF}$ & & & & \\
\hline Between sires . & 27 & 3.2900 & $-\sigma_{\mathrm{W}}^{2}+k_{1} \sigma_{\mathrm{D}}^{2}+k_{2} \sigma_{\mathrm{S}}^{2}$ & $\hat{\sigma}_{\mathrm{S}}^{2}=0.025^{\circ}$ \\
\hline $\begin{array}{l}\text { Between dams within } \\
\text { sires }\end{array}$ & 49 & $2 \cdot 60_{45}$ & $\sigma_{\mathrm{W}}^{2}+k_{1} \sigma_{\mathrm{D}}^{2}$ & $\hat{\sigma}_{\mathrm{D}}^{2}=0.212 \mathrm{I}$ \\
\hline Within full sib families & 607 & $0.74^{82}$ & $\sigma_{\mathrm{W}}^{2}$ & $\hat{\sigma}_{\mathrm{W}}^{2}=0.74^{82}$ \\
\hline \multicolumn{3}{|c|}{$k_{1}=9 \cdot 078_{5}(\mathrm{CS})$} & \multicolumn{2}{|l|}{$\begin{aligned} k_{2}= & 25.7111 \\
24.4004 & (\mathrm{CS})\end{aligned}$} \\
\hline
\end{tabular}

95 per cent. confidence limits:

$$
\begin{array}{lll}
\mathrm{CS}=\mathrm{I} .205<\sigma_{\mathrm{W}}^{2}<\mathrm{I} .439 & 0.177<\sigma_{\mathrm{D}}^{2}<0.465 & -0.017<\sigma_{\mathrm{S}}^{2}<0.23 \mathrm{I} \\
\mathrm{CF}=0.683<\sigma_{\mathrm{W}}^{2}<0.824 & 0.132<\sigma_{\mathrm{D}}^{2}<0.338 & -0.039<\sigma_{\mathrm{S}}^{2}<0.122
\end{array}
$$

appear in place of the $k_{1}$ 's]. However, if these are not equal, $\mathrm{F}$ tests and confidence intervals cannot be obtained. Snedecor suggests using a single value for $k$ which turns out to be intermediate between the exact coefficients. In the present material, heritability estimates were the same to two decimal places using both methods. Therefore, the intermediate $k$ has been used in order to obtain confidence intervals.

Confidence limits for $\sigma_{\mathrm{w}}^{2}$ (variance within full sib families) were obtained from the relation $S S_{\mathrm{W}}=\sigma_{\mathrm{W}}^{2} \chi^{2}\left(\mathrm{~d} f_{\mathrm{w}}\right)$ (Scheffé, I 959, p. 229). Corresponding limits for $\sigma_{\mathrm{D}}^{2}$ and $\sigma_{\mathrm{S}}^{2}$ were obtained using a formula derived by Bulmer (1957). These limits, included in table 3 , indicate that the estimate of $\sigma_{\mathrm{S}}^{2}$ is not too precise.

The sire component, $\sigma_{\mathrm{S}}^{2}$ estimates $\frac{1}{4} \sigma_{\mathrm{A}}^{2}$ plus decreasing fractions of higher order additive $\times$ additive epistatic interactions. In the absence of the latter effects, $4 \hat{\sigma}_{\mathrm{S}}^{2}$ provides an estimate of additive 
genetic variance. The dam component $\hat{\sigma}_{\mathrm{D}}^{2}$ estimates $\frac{1}{4} \sigma_{\mathrm{A}}^{2}+\frac{1}{4} \sigma_{\text {Dom. }}^{2}$ (Dominance Variance) + fractional higher order epistatic terms $+\sigma_{M}^{2}$ (variance due to maternal effects). Thus again ignoring the epistatic interactions, $4 \hat{\sigma}_{\mathrm{D}}^{2}$ includes $\sigma_{\mathrm{A}}^{2}, \sigma_{\text {Dom. }}^{2}$, and $4 \sigma_{\mathrm{M}}^{2}$.

With the assumptions given above regarding epistatic terms, an estimate of narrow-sense heritability from the sire component is given by $4 \theta_{\mathrm{S}}^{2} / \hat{\sigma}_{T}^{2}$ (where $\sigma_{T}^{2}=$ total variance $=\sigma_{\mathrm{S}}^{2}+\sigma_{\mathrm{D}}^{2}+\sigma_{\mathrm{W}}^{2}$ ). A second estimate, from the dam component, $4 \hat{\sigma}_{\mathrm{D}}^{2} / \hat{\sigma}_{T}^{2}$, is biased by dominance and maternal effects. It follows that $\left(\hat{\sigma}_{\mathrm{D}}^{2}-\hat{\sigma}_{\mathrm{S}}^{2}\right) / \hat{\sigma}_{\mathrm{T}}^{2}$ provides an estimate of $\mathrm{M}+\frac{1}{4} \mathrm{H}$, where $\mathrm{H}$ is the proportion of variance due to dominance deviations. If 0.08 and 0.10 are used as estimates of $\mathbf{M}$ for CS and CF respectively (see the previous and following experiments), the latter term can also be used to estimate $H$. The resulting estimates for $h^{2}, \mathrm{M}$ and $\mathrm{H}$ from the nested design are given below:

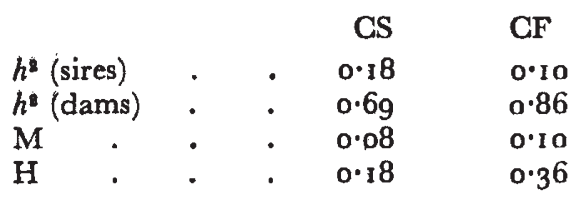

If the assumption that epistatic variance is negligible is a valid one, and the only evidence available indicates that it is at least for CS, and if maternal effects are not greater than assumed, then a fairly large proportion of variance is due to dominance and/or overdominance of genes for developmental rate. The results of two-way selection for rate of development in $T$. castaneum also indicated that dominance contributions to variance are substantial (Dawson, 1965). The fact that developmental rates of $F_{1}$ progeny from the crosses between inbred lines are outside the parental range (table I) is also suggestive of this conclusion.

Confidence limits for sire heritability estimates from the nested design were obtained from intraclass correlation coefficients (Scheffé, I959, p. 229). The resulting limits were $(-0 \cdot 01,0 \cdot 24)$ and $(\multimap \cdot 04$, 0.20 ) for CS and CF respectively.

A diallel crossing scheme, utilising blocks of two males and two females each (Lerner, 1950, p. 158) was also carried out. This was made possible by the observation of Schlager (1960) that in a singlepair mating of CS if one male is substituted for by a second male, after a few days all eggs laid by the female will have been fertilised by the second male.

Fifty blocks were set up for CS and 30 for CF using beetles randomly chosen from the synthetic stocks. Because of time limitations, systematic matings could not be made, so that the matings were spread out over a three week interval. However, within this time range parental age has no significant effect on developmental rate of offspring (Dawson, 1964a). Whenever a second male was placed with a female, six days were allowed prior to collecting eggs in order to insure that sperm $2 \mathrm{C} 2$ 
replacement had occurred. Since some matings failed to produce progeny, only 43 blocks for CS were suitable for analysis. For CF, 28 blocks had offspring for all four matings.

The statistical model used for the analysis of these data is as follows (using the notation of Scheffé, I959) where $\mathrm{Y}_{i j k l}$ is the lth observation from the mating of the $i$ th sire and $j$ th dam in the $k$ th block:

$$
\begin{aligned}
\mathrm{Y}_{i j k l} & =u+a_{i k}+b_{j k}+c_{k}+d_{i j k}+e_{i j k l} \\
\text { where } u & =\text { grand mean, common to all observations } \\
a_{i k} & =\text { effect of the } i \text { th sire in the } k \text { th block } \\
b_{j k} & =\text { effect of the } j \text { th dam in the } k \text { th block } \\
c_{k} & =\text { effect of the } k \text { th block } \\
d_{i j k} & =\text { interaction between the } i \text { th sire and } j \text { th dam in the } \\
& k \text { th block } \\
e_{i j k l} & =\text { random error in the observation. }
\end{aligned}
$$

The $a_{i k}, b_{j k}, c_{k}, d_{i j k}$ and $e_{i j k l}$ are assumed to be independently normal with variances $\sigma_{\mathrm{S}}^{2}, \sigma_{\mathrm{D}}^{2}, \sigma_{\mathrm{C}}^{2}, \sigma_{\mathrm{I}}^{2}$ and $\sigma_{\mathrm{W}}^{2}$ respectively. The model also assumes that there is no effect of aging of parents. As mentioned above, this assumption may be taken as valid.

The data were analysed in two stages. The first step is a simple one-way analysis of variance using all observations to obtain an estimate of $\sigma_{\mathrm{w}}^{2}$. The second analysis, which uses the means of full sib offspring from each mating to obtain the remaining components, is essentially a nested design where the sire and dam effects are completely crossed within blocks. The partition of variance components for this design is given in Lerner (1950, p. ${ }^{158}$ ) for the case of equal numbers of offspring in all cells.

The results of the diallel analyses are given in tables 4 and 5 . From these data estimates of $h^{2}$ and $\mathbf{M}$ may be obtained in the following manner. The sire component, $\hat{\sigma}_{\mathrm{S}}^{2}$, contains the covariance between paternal half sibs, which includes $\frac{1}{4}$ of the additive genetic variance plus fractional higher order additive $\times$ additive epistatic terms $\left(\frac{1}{18} \sigma_{\mathrm{AA}}^{2}+\frac{1}{B 4} \sigma_{\mathrm{AAA}}^{2}+\ldots\right)$. Thus, ignoring the latter terms, $4 \hat{\sigma}_{\mathrm{S}}^{2} / \hat{\sigma}_{\mathrm{T}}^{2}$ provides

\begin{tabular}{|c|c|c|c|}
\hline & & CS & $\mathrm{CF}$ \\
\hline$h^{2}$ (sires) & . & 0.13 & 0.13 \\
\hline$h^{2}$ (dams) & • & $0.4 \mathrm{I}$ & 0.53 \\
\hline $\mathrm{M}$ & 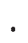 & 0.07 & 0.10 \\
\hline
\end{tabular}
an estimate of narrow sense heritability (where $\sigma_{\mathrm{T}}^{2}=$ total variance $\left.=\sigma_{\mathrm{S}}^{2}+\sigma_{\mathrm{D}}^{2}+\sigma_{\mathrm{I}}^{2}+\sigma_{\mathrm{W}}^{2}\right)$. Similarly, the dam component measures covariance between maternal half sibs, and includes maternal effects in addition to additive genetic effects. Thus, with reservations as noted previously concerning the actual source of maternal effects, $4 \hat{\sigma}_{\mathrm{D}}^{21} / \hat{\sigma}_{\mathrm{T}}^{2}$ estimates $h^{2}+4 \mathrm{M}$, and from this it follows that $\mathbf{M}=\left(\hat{\sigma}_{\mathrm{D}}^{2}-\hat{\sigma}_{\mathrm{S}}^{2}\right) / \hat{\sigma}_{\mathrm{T}}^{2}$. Estimates for $h^{2}$ and $\mathbf{M}$ are given below:

The interaction component in a diallel design of the type used here contains $\frac{1}{4} \sigma_{\text {Dom. }}^{2}+$ epistatic terms. One supposed advantage of diallel 
designs is that they provide estimates of the extent of non-additive genetic effects. However, as Miller Legates and Cockerham ( ${ }_{9} 6_{3}$ ) have recently pointed out, this component is biased by time effects

TABLE 4

Analysis of variance for a diallel design for CS. The analysis is done in two stges as explained in the text

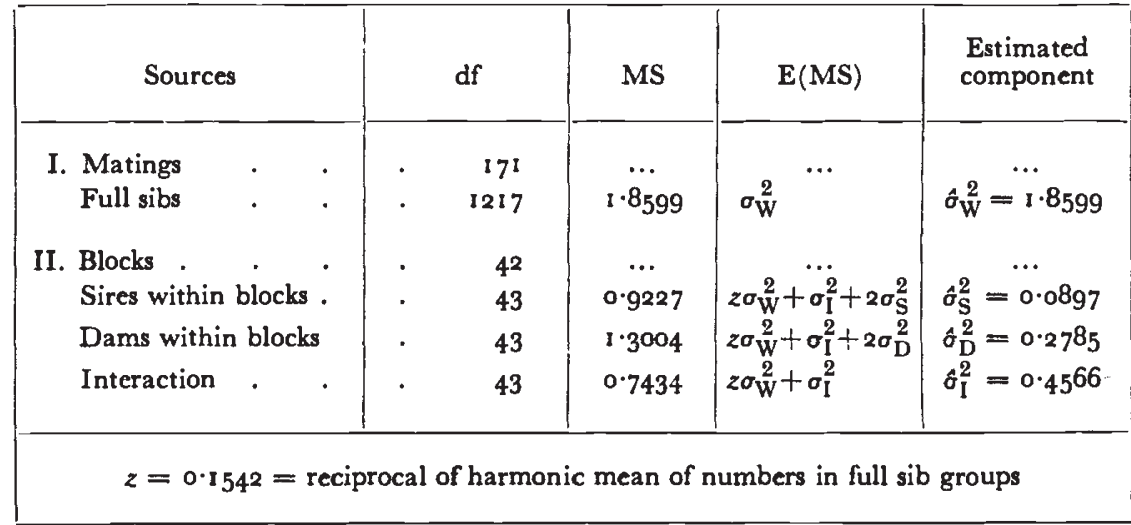

95 per cent. confidence limits:

$1.74^{2}<\sigma_{\mathrm{W}}^{2}<1.991 \quad 0.028<\sigma_{\mathrm{D}}^{2}<0.5^{84}-0.13^{6}<\sigma_{\mathrm{S}}^{2}<0.334$

and interaction between genotype of offspring and maternal environment. Assuming that epistasis is negligible, $4 \hat{\sigma}_{\mathrm{I}}^{2} / \hat{\sigma}_{\mathrm{T}}^{2}$ estimates $\mathrm{H}$. It is quite obvious that $\mathrm{H}$ is overestimated in these experiments; the resulting estimates for CS and CF being 0.68 and 0.57 respectively.

TABLE 5

Analysis of variance for diallel design for $C F$

\begin{tabular}{|c|c|c|c|c|}
\hline Sources & $\mathrm{d} f$ & MS & $\mathbf{E}(\mathbf{M S})$ & $\begin{array}{l}\text { Estimated } \\
\text { component }\end{array}$ \\
\hline I. Matings & II & $\cdots$ & & \\
\hline Full sibs & 832 & 0.4372 & $\sigma_{\mathrm{W}}^{2}$ & $\hat{\sigma}_{\mathrm{W}}^{2}=0.4372$ \\
\hline II. Blocks . & 27 & $\cdots$ & & ${ }^{2} \cdots$ \\
\hline Sires within blocks & 28 & $0 \cdot 1986$ & $z \sigma_{\mathrm{W}}^{2}+\sigma_{\mathrm{I}}^{2}+2 \sigma_{\mathrm{S}}^{2}$ & $\hat{\sigma}_{\mathrm{S}}^{2}=0.0204$ \\
\hline Dams within blocks & 28 & 0.3247 & $z \sigma_{\mathrm{W}}^{2}+\sigma_{\mathrm{I}}^{2}+2 \sigma_{\mathrm{D}}^{2}$ & $\hat{\sigma}_{\mathrm{D}}^{2}=0.0834$ \\
\hline Interaction . & 28 & 0.1578 & $z \sigma_{\mathrm{W}}^{2}+\sigma_{\mathrm{I}}^{2}$ & $\hat{\sigma}_{1}^{2}=0.0908$ \\
\hline
\end{tabular}

$z=0.1532=$ reciprocal of harmonic mean of numbers in full sib groups.

95 per cent. confidence limits

$0.404<\sigma_{\mathrm{W}}^{2}<0.475 \quad 0.011<\sigma_{\mathrm{D}}^{2}<0.186 \quad-0.045<\sigma_{\mathrm{S}}^{2}<0.08 \mathrm{t}$

Thus in spite of the fact that maternal age does not seem to be an important factor, the objections of Miller et al. $\left(\mathrm{Ig}^{6} \mathrm{C}_{3}\right)$ to the diallel scheme as used to estimate non-additive variance seem to be justified. 
Confidence limits for $\sigma_{\mathrm{W}}^{2}$ and for $\sigma_{\mathrm{S}}^{2}$ and $\sigma_{\mathrm{D}}^{2}$, given in tables 4 and 5 , were again obtained using methods of Scheffé (1959) and Bulmer (1957) respectively. As was the case with the nested design, the confidence limits for $\sigma_{S}^{2}$ are quite large.

A final method for partial partitioning of phenotypic variance involves the comparison of variance in outbred populations with that of $F_{1}$ hybrids between highly inbred lines (see, for example, Robertson, 1957). The synthetic stocks were used as outbred populations. Data from assays of these stocks at several different times were combined in order to provide a more accurate estimate of phenotypic variance. Comparable results from two $F_{1}$ hybrids of each species (including

TABLE 6

Phenotypic variances and components of variance derived from synthetic (outbred) stocks and $F_{1}$ hybrids from crosses between inbred lines

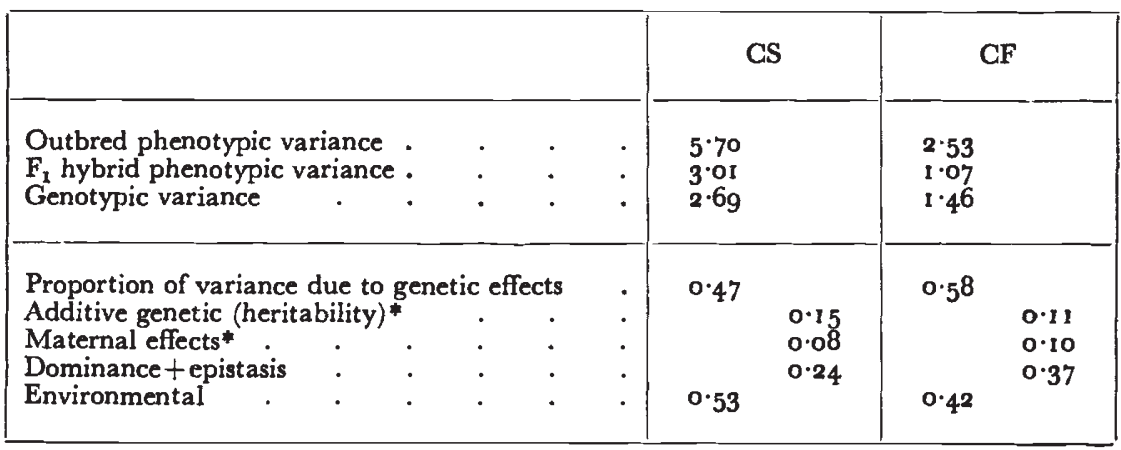

* Combined estimates from data of table 7.

the same ones used in the test for epistasis described earlier) were used to estimate variance in populations of uniform genotype. The latter estimate includes only variance due to environmental effects. The estimate from the outbred stocks includes variation resulting from both genetic and environmental sources.

The pooled data are presented in table 6. They indicate that total genetic variance is proportionally higher in CF than CS. Utilising estimates of $h^{2}$ and $\mathrm{M}$ taken from combined results of all previous tests (table 7) provides estimates of the contribution of dominance plus epistatic effects to total variance. This component is seen to be higher for $\mathrm{CF}$ than $\mathrm{CS}$ and agrees quite well with estimates of dominance from the nested designs, assuming as before that epistasis is negligible.

Utilising this method, Robertson (1957) found that 52 per cent. of phenotypic variation in developmental rate of Drosophila melanogaster was due to genetic sources. Having no narrow-sense heritability estimate, he did not break this down into additive and non-additive components. At any rate his estimate for proportion of the total genetic variance is similar to those obtained for CS and CF in the present analysis. 
Objection to the use of this procedure for partitioning variance has been raised by Bray, Bell and King ( 1962 ) on the grounds that the inbred lines used must certainly not be representative of the original population from which they were taken. However, in combination with the other methods used, this technique seems to be quite a reasonable one. In the present material, it yielded estimates very similar to those obtained using other designs.

\section{DISCUSSION}

The estimates obtained from all designs tested, with confidence limits where applicable, are summarised in table 7 . In addition to

TABLE 7

Summary of estimates of heritability $\left(\mathrm{h}^{2}\right)$, maternal effects $(M)$ and dominance effects $(H)$ for $C S$ and $C F .95$ per cent. confidence limits for $\mathrm{h}^{2}$ included where applicable

\begin{tabular}{|c|c|c|c|c|c|c|}
\hline \multirow{2}{*}{ Experiment } & \multicolumn{3}{|c|}{ CS } & \multicolumn{3}{|c|}{ GF } \\
\hline & $h^{2}$ & $\mathrm{M}$ & $\mathrm{H}$ & $h^{2}$ & M & $\mathrm{H}$ \\
\hline Regression (random) . & 0.12 & 0.09 & $\cdots$ & $\cdots$ & $\cdots$ & $\cdots$ \\
\hline Nested . & 0.19 & $\cdots$ & 0.18 & 0.10 & $\ldots$ & $0 \cdot 3^{6}$ \\
\hline Diallel . . . & $0_{13}$ & 0.07 & $(0.68) *$ & 0.13 & 0.10 & $(0.57)^{*}$ \\
\hline $\begin{array}{c}\text { Outbred vs. Inbred } \\
\text { Selectiont }\end{array}$ & $\begin{array}{l}\ldots \\
0 \cdot 14\end{array}$ & $\begin{array}{l}\ldots \\
\ldots\end{array}$ & $\begin{array}{c}0.24 \\
\ldots\end{array}$ & $\begin{array}{c}\cdots \\
0.17\end{array}$ & $\begin{array}{l}\ldots \\
\ldots\end{array}$ & $\begin{array}{c}0.37 \\
\ldots\end{array}$ \\
\hline II & $\begin{array}{c}(0 \cdot 11,0 \cdot 18) \\
0 \cdot 14 \\
(0.08,0 \cdot 20)\end{array}$ & & & $\begin{array}{c}(0.11,0.24) \\
0.12 \\
(0.04,0.20)\end{array}$ & & \\
\hline $\begin{array}{l}\text { Inbred } \\
\text { Selection } \\
\ddagger\end{array}$ & $0 \cdot 20$ & ... & $\cdots$ & 0.13 & $\cdots$ & $\cdots$ \\
\hline II & $\begin{array}{c}(0.0 .15 \\
0.150 .07)\end{array}$ & $\cdots$ & $\cdots$ & $\begin{array}{c}(0.09 \\
0.09 \\
-0.10 .0 .28)\end{array}$ & $\cdots$ & $\cdots$ \\
\hline III & ... & $\cdots$ & $\cdots$ & $\left(\begin{array}{c}0.09 \\
-0.21,0.41)\end{array}\right.$ & $\cdots$ & $\cdots$ \\
\hline IV & $\cdots$ & $\cdots$ & $\cdots$ & $\begin{array}{c}0.04 \\
(-0.20,0 \cdot 28)\end{array}$ & $\cdots$ & $\cdots$ \\
\hline Combined estimate & $0 \cdot 15$ & 0.08 & 0.21 & O.II & $0 \cdot 10$ & $0 \cdot 3^{6}$ \\
\hline
\end{tabular}

* Not included in combined estimates (see text).

† Based on 7 generations of selection for fast (I) and slow development (II) in CS and 9 generations of selection for fast development in two CF lines.

+ Based on 4 generations of selection for fast development in $F_{2}$ populations formed by crossing inbred lines.

the designs discussed in the preceding section, realised heritability estimates were available from lines selected for fast and slow development in CS, for fast development in GF (2 replicates) and from selection in $\mathrm{F}_{2}$ populations of hybrids from crosses between inbred lines (Dawson, I 965). These estimates are also included in table 7 . Combined estimates of heritability $\left(h^{2}\right)$, maternal effects $(\mathrm{M})$ and dominance effects $(\mathbf{H})$ were calculated as unweighted means of all available 
observations. Estimates of $\mathrm{H}$ from the diallel design were not included for reasons previously cited.

It may be concluded on the basis of these combined estimates that total genotypic variance is proportionally higher in CF and that the majority of this difference is due to a greater dominance component.

It was assumed throughout the presentation that epistatic contributions to variance were relatively unimportant in the CS and CF synthetic strains. One test for epistasis in each species carried out with inbred material indicated that this assumption was a reasonable one. A more convincing argument stems from the nature of the synthetic strains, which have been maintained as closed populations for a number of years. As Mayr ( 1963 ) points out, it might be expected that epistasis would be less important and overdominance more important as sources of genetic variability in such populations. In natural populations which are continually subject to gene flow in the form of migration a greater amount of epistasis would interact well in many combinations. In closed populations there is less need for such genes, and in fact, as Dobzhansky and Spassky (1962) have shown, closed populations can evolve overdominance.

One of the primary uses of estimates of components of genetic variance is in the prediction of expected gain in an artificial selection programme. Extensive experiments carried out by Clayton, Morris and Robertson (1957) and Clayton and Robertson (1957) indicated that short-term selection responses were adequately predicted on the basis of heritability estimates on the foundation population. Longterm responses, on the other hand, diverged significantly from the expected results.

Similar results were obtained with artificial selection for fast and slow development from the CS synthetic stock. Realised heritability estimates from 7 generations of selection, listed in table 7 , were in accord with theoretical predictions. After I3 generations, however, realised heritabilities were $0.1 \mathrm{I}$ and 0.32 for the fast and slow lines respectively. These results have been examined in detail elsewhere (Dawson, 1965).

Nine generations of selection for fast development in two replicate CF lines initiated from the synthetic stock also yielded realised heritability estimates in accord with prediction (table 7). Thus, as in the studies of Clayton et al. cited above, short-term responses to selection follow those expected from a knowledge of heritability, whereas longterm results do not. The large component of genetic variance attributable to dominance (and possibly epistatic) effects is probably the key to the failure of long-term selection progress to conform to that expected from theory (Lerner, I958).

Finally, it is of interest to compare some of the designs available for estimating variance components. Important considerations in this comparison are: (I) the labour and facilities required to perform 
the experiments; (2) the various estimates obtainable from these designs; and (3) the accuracy of the estimates.

Parent-offspring regression techniques are probably the easiest to carry out in terms of labour and space requirements. The use of offspring means avoids problems of non-normality in the distribution of the trait being utilised. This design suffered, at least in the present study, from a large standard error of the estimate of heritability. If parents are mated assortatively, considerably greater precision is obtained (Reeve, r953, r955, I96r). When maternal effects are important, however, a large overestimate of heritability can result from assortative mating (Dawson, $1964 b$ ).

For estimation of maternal effects, the diallel design used here is excellent. The genetic variances obtained from sire and dam components in this design are identical with the exception of maternal effects, present only in the dam component. This method required the most time and facilities and, in addition, is limited to organisms where the same female can be mated to more than one male. More elaborate diallel designs which utilise a number of inbred lines (see, for example, Hayman, I954; Jinks and Broadhurst, 1963) suffer from assumptions which, in some cases, may be unrealistic. Evidence of problems relating to the use of diallel matings to estimate nonadditive genetic variance (Miller, Legates and Cockerham, I963) are confirmed in the present studies.

The nested design also requires a considerable amount of labour and space, but provides a more accurate estimate of heritability than conventional parent-offspring regression methods. The excess of dam over sire components in this design gives a notion of the extent of non-additive genetic variance and maternal effects relative to heritability.

The other two methods reported here involve the use of inbred lines which in most instances will not be representative of the original foundation population. Comparison of varianies in nitbred and genetically uniform lines is quite easy to carry out $\omega_{\lrcorner,}$, if un $_{\text {estimate }}$ of heritability is available from other sources, provides an indication of the extent of non-additive genetic variance. A further problem here, however, is that environmental variance of $F_{1}$ hybrids may be underestimated because of buffering properties associated with heterozygosity. The use of Mather's (1949) techniques for estimating variance components from inbred lines and their derivatives requires that environmental variance in the inbred and $F_{1}$ populations be made equal, and this is not always easy to accomplish.

Heritability estimates from replicated artificial selection lines are, of course, very good, but require a considerable amount of time and material. Perhaps several single-generation selection experiments (similar to parent-offspring regression methods where parents are mated assortatively) would be easier to do. However, if additive $x$ additive epistatic interactions are an important source of variance, 
heritability can be overestimated in single-generation studies (Griffing, 1960).

\section{SUMMARY}

Several methods of estimating components of phenotypic variance are compared using developmental rate in synthetic laboratory populations of the flour beetles, Tribolium castaneum (CS) and $T$. confusum $(\mathrm{CF})$.

Combined estimates of the proportionate contributions to total variance of additive genetic effects, maternal effects and dominance effects from these various designs were $0.15,0.08$ and 0.21 respectively for $\mathrm{CS}$ and $0.1 \mathrm{I}, 0.10$ and 0.36 for $\mathrm{CF}$. Total genotypic variance is thus higher in $\mathrm{CF}$, and the difference is due to a higher dominance component.

Short-term gains from artificial selection for developmental rate were in accord with those predicted from heritability estimates, but long-term responses diverged from expectations. The latter differences are thought to be attributable to the relatively large dominance component of variance.

The various methods utilised are compared in terms of the labour and facilities required, the types of components estimable, and the accuracy of the estimates.

Acknowledgments.-I am indebted to Drs E. R. Dempster and J. C. De Fries for valuable suggestions for improvement of the manuscript, and to Mrs Louise Bielfelt, Mrs Barbara Strong and Mr Nobuo Inouye for technical assistance. This research was carried out during the tenure of a fellowship awarded by the University of California from funds made available by the Woodrow Wilson Foundation, the Charles A. Kofoid Eugenics Fellowship, an N.I.H. Genetics Training Grant (USPHS-5 $\mathrm{T}_{1}-\mathrm{GM}-367$ ) and was supported in part by USPHS grant GM-8942 to Dr I. M. Lerner. I am also grateful to Professor Lerner, who guided me throughout my research work.

\section{REFERENCES}

ANDERSON, V. L., ANE KEMPthoRNe, O. 1954. A model for the study of quantitative inheritance. Genetics, 39, 883-898.

BOX, G. E. P. I953. Non-normality and tests on variances. Biometrika, 40, 318-335. BRAY; D. F., BELL, A. E., AND KING, s. C. 1962. The importance of genotype by environment interactions with reference to control populations. Genet. Res., $3,282-302$.

BULMER, M. G. I957. Approximate confidence limits for components of variance. Biometrika, 44, I59-167.

CLAYTON, G. A., MORRIS, J. A., AND ROBERTSON, A. 1957. An experimental check on quantitative genetic theory. I. Short-term responses to selection. F. Genet. $55,13^{1-1} 5^{1}$.

CLAYTON, G. A., AND ROBERTSON, A. 1957. An experimental check on quantitative genetic theory. II. The long-term effects of selection. F. Genet., 55, I 52-1 70.

Cockerham, c. c. 1956. Analysis of quantitative gene action. Brookhaven Symp. Biol., 9, 53-68.

COMSTOCK, R. E., AND ROBINSON, H. F. 1952. Estimation of average dominance of genes, pp. 494-516 in Heterosis, ed. J. W. Gowen. Iowa State College Press, Ames. 
DAwson, P. s. 1964a. The genetics of developmental rate and its relationship to competitive ability in Tribolium. Ph.D. Dissertation, University of California, Berkeley.

DAwson, P. S. 1946b. The use of assortative mating for heritability estimation. Genetics, 49, $99^{1-994 .}$

DAwson, P. S. I 1965 . Genetic homeostasis and developmental rate of Tribolium. Genetics, $51,873-885$.

DOBZHANSKY, TH., AND SPASSKy, B. 1962. Genetic drift and natural selection in experimental populations of Drosophila pseudoobscura. Proc. Nat. Acad. Sci., $48,14^{8-1} 57$.

FAlCONER, D. s. 1960. Introduction to Quantitative Genetics. Oliver and Boyd, London.

FISHER, R. A. I918. The correlation between relatives on the supposition of Mendelian inheritance. Trans. Roy. Soc. Edinburgh, 52, 399-433.

GRIFFING, B. 196o. Theoretical consequences of truncation selection based on the individual phenotype. Aust. J. Biol. Sci., 13, 307-343.

HAYMAN, B. I. 1954. The theory and analysis of diallel crosses. Genetics, 39, 789-8og.

Howe, R. W. I96I. Developmental time and weight in Tribolium castaneum. Tribolium Info. Bull., 4, $21-22$.

JiNKs, j. L., AND BROADhURST, P. L. 1963. Diallel analysis of litter size and body weight in rats. Heredity, $18,3^{19-3} 6$.

Lerner, I. M. 1950. Population Genetics and Animal Improvement. Cambridge Univ. Press, London.

LERNER, J. M. 1958. The Genetic Basis of Selection. John Wiley and Sons, New York.

LERNER, I. M., AND Ho, F. K. I96r. Genotype and competitive ability of Tribolium species. Amer. Naturalist, 95, 329-343.

MATHER, K. 1949. Biometrical Genetics. Methuen, London.

MaYr, E. 1963. Animal Species and Evolution. Harvard Univ. Press, Cambridge.

MILleR, R. H., LEGATES, J. E., AND COCKeRHAM, C. C. 1963. Estimation of nonadditive hereditary variance in traits of mice. Genetics, 48, 177-188.

REEVE, E. C. R. I953. Studies on quantitative inheritance. III. Heritability and genetic correlation in progeny tests using different mating systems. F. Genet., $51,520-542$.

REeVE, E. C. R. 1955. (Contribution to discussion.) Cold Spring Harbor Symp. Quant. Biol., 20, 76-78.

REEVE, E. C. R. 1961 . A note on non-random mating in progeny tests. Genet. Res., 2, $195-203$.

ROBERTSON, F. W. 1957. Studies in quantitative inheritance. XI. Genetic and environmental correlation between body size and egg production in Drosophila melanogaster. 7. Genet., 55, 428-443.

sCHEFFE, H. 1959. The Analysis of Variance. John Wiley and Sons, New York.

SCHLAGER, G. 196o. Sperm precedence in the fertilisation of eggs in Tribolium castaneum. Ann. Entomol. Soc. Amer., 53, 557-56o.

SNedecor, G. W. I956. Statistical Methods. Iowa State College Press, Ames. 